\title{
Demography Beyond the Foot
}

Jenny Trinitapoli

Follow this and additional works at: https://knowledgecommons.popcouncil.org/series_pdr_essays-covid How does access to this work benefit you? Let us know!

\section{Recommended Citation}

Trinitapoli, Jenny. "Demography Beyond the Foot." In Covid-19 and the Global Demographic Research Agenda, edited by Landis MacKellar and Rachel Friedman, 68-72. New York: Population Council, 2021. 


\title{
Demography Beyond the Foot
}

\author{
JENNY TRINITAPOLI
}

WHEN JOHN GRAUNT wrote about the plague in 1687, he understood that mortality statistics have an importance beyond the task of counting. He noted that “...most of them who constantly took in the weekly Bills of Mortality made little other use of them than to look at the foot how the burials increased or decreased [emphasis added]." It is a stark visual, the foot. I thought about that visual in a new way in February 2020, while teaching Graunt to 18 undergraduates, crowded around a table designed for 15. Although I had read Graunt's Observations multiple times before, that "foot" struck a different chord this time. In the context of a mysterious disease circulating and the ominous knowledge that any airborne virus could not be contained to a particular geography, that foot conjured corpse rather than metaphor.

In the months since, I have thought frequently about John Graunt toiling away by candlelight to convert $50+$ years of weekly tabulations of baptisms and burials into something orderly that could reveal statistical regularities of mortality. Reflecting on what kind of work demographers need to be doing now, and in the decades ahead, I see two giant boulders our field needs to collectively move, and they are not so different from those Graunt started to roll. The first is technical, about the present, and focused on measurement: it is a hymn of praise to the good estimate and a valorization of the indispensable work of counting well. The second is more intellectual; it concerns the future, specifically what will need to be researched in the next 5 to 50 years.

Let us consider first the urgent task: counting to create a clear account of the present. Now, some 350 years after Graunt, our vital registration systems remain patchwork, incomplete, and flawed; our cause-of-death declarations are politicized and imprecise; and these Covid-19 test-positivity rates are guesswork, at best. Nonetheless, we are awash in data, with dozens of Covid-19 dashboards and apps to choose from. Some are calling Covid-19 our first "data-driven pandemic."

A population perspective is crucial for enumerating our current crisis and ensuring the quality of our estimates. Demographers need to keep beating the same drum we always beat: principles of representative sampling, careful

Jenny Trinitapoli, Department of Sociology, University of Chicago.

POPULATION AND DEVELOPMENT REVIEW I ESSAYS (FEBRUARY 2021) 
definition of the population at-risk, and correspondence between numerator and denominator. Test-positivity rates are a terrible foundation for any kind of inference. Sentinel surveillance programs have not and will not generate reliable estimates of prevalence or incidence. We learned from the AIDS crisis that HIV prevalence could not be proxied by clinical case studies or data from antenatal checkups; we relied on those estimates for too long, and when the global community finally transitioned to a population-based perspective, we discovered that seroprevalence was far lower than previously estimated. The mortality burden we had understood as a reflection of 30 percent prevalence was actually the consequence of a force much smaller in quantity but more potent in fatality.

A year into the Covid-19 crisis, we have a better handle on case-fatality ratios and death rates than we did for HIV after 20 years. We have rapid tests and sophisticated models but still too few population-based studies. Political leaders across the globe are making major policy decisions without the benefit of basic parameters like age-specific prevalence or a clear and consistent community-level incidence rate. Whether to attribute this failure to a lack of resources, a difference in perspective between demographic principles and the habits of clinical research, or a lack of leadership from demographers remains unclear. I venture that Graunt would be amused by our elaborate tools for displaying data and appalled to see us relying on data plagued by many of the same, irresolvable, interpretive issues that he confronted. The trustworthy denominator is a thing worth fighting for; demographers would do well to get behind the clear and simple message that we cannot safely navigate this pandemic_-or future ones-without population-based estimates generated from representative samples.

In the short-run, I expect that the widely circulating facts about Covid-19 will continue to focus on quantities: in particular, the daily case count, the test-positivity rate, hospitalizations, and the daily and cumulative mortality burden. A key lesson from the first 12 months of Covid-19 is that the work of generating sound estimates should not be dismissed as mere counting. If anything, this abundance of new data sources reinforces old lessons from earlier plagues: that vital statistics are difficult to keep, especially so in an emergency.

Our Covid dashboards operate on a second level, unrelated to quantities; they fuel what I call population chatter. Graunt wrote that the Bills of Mortality were, for most, merely "a text to talk upon." And talk, we do. At dinner tables and among WhatsApp groups across the globe, the daily and weekly Covid numbers provide fodder for everyday conversation, and the numbers never speak for themselves. Through population chatter-ongoing conversations with socially salient others about demographic phenomena (including but not limited to mortality rates) -individuals and families weigh evidence, narrate the trade-offs between acceptable versus unacceptable risks, make 
personal decisions about how to protect their families and communities, and process unthinkable losses.

Demographers must counter the characterization of Covid-19 as "different" in some fundamental way because of the vast amount of data at our fingertips. People living through this moment do not experience the world by weekly rates; they perceive mortality risk through the experiences of their own social network. When ordinary people engage in population chatter, they are arguing about causation, assigning blame, distinguishing good deaths from bad deaths, and assessing the overall risk environment. Through our narration of the deaths we observe and the illness that preceded them, our conversations about Covid are moralized and politicized, as was the case with AIDS, with the 1918 influenza, with the cholera outbreaks of the nineteenth century, and by Graunt, who asked whether new reigns of kings brought with them new plagues. We are, just as they were, living through a season of confusion that will be resolved, not by facts alone, but by facts organized through the cognitive and moral frames we build to make sense of it all.

The other challenge before us concerns what to research next. Taking a page from the best examples of historical demography and demographic history, it is safe to say that the imprint of a major disease event will be manifest not only in those who die from the novel coronavirus but in the lives of those who survive, in the institutions that crumble and those that persist, and in the cultural practices and social norms that endure and adapt. In other words, it may not be the increase in mortality-the Malthusian oscillation of 2020/21 - that commands our attention in the long run. As with other major historical epidemics, we will need to analyze Covid-19 as a test of our social and political structures.

Demographers need to contribute, of course, to a first wave of research (and this is already under way) that specifies the immediate effects of Covid-19 on mortality, morbidity, and bereavement with an emphasis on inequality. Getting this right is hugely important; it will be controversial and politically consequential. This is the corpse-part of mortality research-the foot as foot. Count, classify, compare, repeat ad infinitum. To the extent that our research can both expose and address the fault lines of inequality that structure contemporary populations, this work may be more moral reckoning than estimation problem.

A second wave of demographic research will look beyond mortality and address the immediate consequences of Covid-19 for family life at both the micro- and macro-levels. Graunt pondered the difference between burials and christenings; we will inquire about nuptiality and divorce rates, agespecific fertility rates, and family structure. To elaborate just one example, the consequences for fertility will be manifest in volitional and biological pathways. Among women aged 25-45 across Covid-affected contexts, I expect to see immediate changes through fertility reductions and delays. We will not 
be surprised to observe lengthening birth intervals among parents of small children who lack reliable childcare during Covid times-a household-level response. Some reductions will be volitional, due to economic precarity or a lack of extended-family support, while others will be biological as a result of postponement: when women nearing the end of their reproductive lives delay, they may end up having "chosen" to reduce. Because demographers are concerned with the way the whole of a population looks, we may see a renewed attentiveness to age-structure and the multigenerational impact of Covid disruptions in a life-course framework, the consequences of which will play out over decades, not years.

Perhaps the most important suggestion for thinking beyond the foot is present in Graunt's seldom-mentioned subtitle to The Observations: "With reference to the Government, Religion, Growth, Ayre, Diseases, and the several Changes of Said City." Thinking beyond the foot requires us to link our knowledge of mortality and morbidity burdens, in particular, to some questions of ultimate concern. The consequences of Covid-19 as a disease event will bring changes to our religious rituals, burial rites, our routines of food preparation, and ethics of obligation to kin, to neighbors coping with long-term morbidities, and to the earth. Here, we must venture outside of conventional demographic territory to start and sustain conversations with adjacent disciplines and subfields; such exchange may bring new opportunities to export and enrich demographic knowledge and approaches.

Take religious rituals and doctrines: Christians across the globe cannot safely gather in their parishes to sing beloved hymns and drink from a shared cup right now. Virtual Islamic platforms are sustaining daily and weekly prayers while observing social-distancing recommendations. New funeral rites, religious and secular, including the drive-through-wake and Zoom shiva are emerging before our eyes. Young people are improvising expressions of collective grief that combine a new understanding of universal precautions with the nonnegotiable elements of their parents' rituals. All of this can be productively analyzed within a framework of demographic change, and a keen ear to population chatter may help us solve some puzzles about which things change and which stay the same in the wake of this pandemic.

While religious practices are often thought of as settled or fixed, previous research from a population perspective shows that religious teachings and practices are dynamic and responsive to demographic realities. Specific rituals may change quickly, but the consensus positions to justify them unfold over longer periods of time; these tend to be organized around an ethos (e.g., healthfulness and stability to promote social reproduction in families and communities) rather than articulated as a set of practical concerns. We are hearing critiques of the built environment and calls to reform our parks, roads, public restrooms, apartment buildings, hospitals, and schools in the interest of hygiene and health, religious and secular. These critiques echo 
choruses of social-gospel-style reform from the Progressive Era. For social gospelers, managing plague required scientific knowledge, the reparation of broken social relationships, and the creation of new safety-nets and structures of care. A scientifically informed project of social redemption to address the casualties of Covid is imminent, and while it may not be explicitly religious or unified, its underpinnings will be moral, particular, and contested.

I'll make these points again in February 2021, when I teach Graunt to 19-year-olds-this time masked and distanced in an awkwardly oversized classroom. Good estimates are worth toiling over, and the residue of Covid-19 will not be confined to the demographic sphere. The ordinary work of enumeration, classification, and comparison is, in some fundamental way, a moral project, and the religious and political transformations that seem, to many, like acts of divine revelation may have a more prosaic explanation: demographic change. What a profound paradox we find in that foot. 